Subscriber access provided by Caltech Library

\title{
Article
}

\section{The Origins of the Stereoretentive Mechanism of Olefin Metathesis with Ru-Dithiolate Catalysts}

Jessica M. Grandner, Huiling Shao, Robert H. Grubbs, Peng Liu, and Kendall N. Houk

J. Org. Chem., Just Accepted Manuscript • DOI: 10.1021/acs.joc.7b02129 • Publication Date (Web): 25 Aug 2017

Downloaded from http://pubs.acs.org on August 28, 2017

\section{Just Accepted}

"Just Accepted" manuscripts have been peer-reviewed and accepted for publication. They are posted online prior to technical editing, formatting for publication and author proofing. The American Chemical Society provides "Just Accepted" as a free service to the research community to expedite the dissemination of scientific material as soon as possible after acceptance. "Just Accepted" manuscripts appear in full in PDF format accompanied by an HTML abstract. "Just Accepted" manuscripts have been fully peer reviewed, but should not be considered the official version of record. They are accessible to all readers and citable by the Digital Object Identifier (DOI®). "Just Accepted" is an optional service offered to authors. Therefore, the "Just Accepted" Web site may not include all articles that will be published in the journal. After a manuscript is technically edited and formatted, it will be removed from the "Just Accepted" Web site and published as an ASAP article. Note that technical editing may introduce minor changes to the manuscript text and/or graphics which could affect content, and all legal disclaimers and ethical guidelines that apply to the journal pertain. ACS cannot be held responsible for errors or consequences arising from the use of information contained in these "Just Accepted" manuscripts. 
The Origins of the Stereoretentive Mechanism of Olefin Metathesis with Ru-Dithiolate Catalysts

\author{
Jessica M. Grandner, ${ }^{\dagger}$ Huiling Shao, ${ }^{\ddagger}$ Robert H. Grubbs,\# Peng Liu, ${ }^{\ddagger *}$ K. N. Houk ${ }^{\dagger *}$ \\ $\dagger$ Department of Chemistry and Biochemistry, University of California, Los Angeles, California \\ 90095, United States \\ \$ Department of Chemistry, University of Pittsburgh, Pittsburgh, Pennsylvania 15260, United \\ States \\ \# The Arnold and Mabel Beckman Laboratory of Chemical Synthesis, Division of Chemistry and \\ Chemical Engineering. California Institute of Technology, Pasadena, California 91125, United \\ States
}

\begin{abstract}
A comprehensive computational study of stereoretentive olefin metathesis with $\mathrm{Ru}$ dithiolate catalysts has been performed. We have determined how the dithiolate ligand enforces a side-bound mechanism and how the side-bound mechanism allows for stereochemical control over the forming olefin. We have used density functional theory (DFT) and ligand steric contour maps to elucidate the origins of stereoretentive metathesis with the goal of understanding how to design a new class of E-selective metathesis catalysts.
\end{abstract}

\title{
Introduction
}

Since the advent of olefin metathesis catalysts, control of product olefin stereochemistry (Figure 1) has been an elusive goal. In the cross-metathesis of two alkenes, E-olefins are frequently obtained as the major product due to the thermodynamic preference for $E$ - over $Z$ isomers. This thermodynamic favoring of $E$-olefin formation often leads to only moderate selectivity that varies from product to product, exemplified by ring-closing metathesis. ${ }^{1}$ Thus, kinetic control of olefin stereochemistry is highly desirable. Recently, catalysts have been developed that favor kinetically the formation of thermodynamically unfavorable Z-olefins with $>95 \%$ selectivity. These catalysts have been successfully applied to various Z-selective metathesis reactions including cross-metathesis, ring-closing metathesis, ring-opening crossmetathesis (ROCM) and ring-opening metathesis polymerization (ROMP). ${ }^{2}$ In 2016, Schrock, Hoveyda, and coworkers synthesized the first Mo-based E-selective metathesis catalysts. ${ }^{3}$ However, ruthenium-based catalysts that provide the same high kinetic selectivity for formation of E-olefins have not yet been developed. In 2013, Hoveyda and coworkers synthesized dithiolate ligated Ru-based catalysts. ${ }^{4}$ While thiolates have been used as ligands for Ru-based metathesis catalysts prior to their report, ${ }^{5}$ the geometry of the dithiolates used by Hoveyda allows for high $Z$-selectivity in ROCM and ROMP. Their computational studies revealed ring-opening cross metathesis occurs via a side-bound mechanism that kinetically favors formation of $Z$ olefins. They subsequently demonstrated the ability of these catalysts to perform $Z$-selective cross metathesis of acyclic olefins. ${ }^{6}$ In 2016 , a series of ruthenium-based dithiolate catalysts, 1-4 in Figure 2a, were synthesized and tested by the Grubbs laboratory. ${ }^{7}$ These complexes were able to catalyze the cross-metathesis of internal olefins with retention of starting olefin stereochemistry. Z-olefins were selectively converted to new $Z$-olefins while $E$-olefins were selectively converted into new $E$-olefins. ${ }^{7}$ This stereoretentive transformation provided the first example of kinetically controlled $E$-selective olefin cross-metathesis with Ru-based catalysts. 
Stereoselective Metathesis
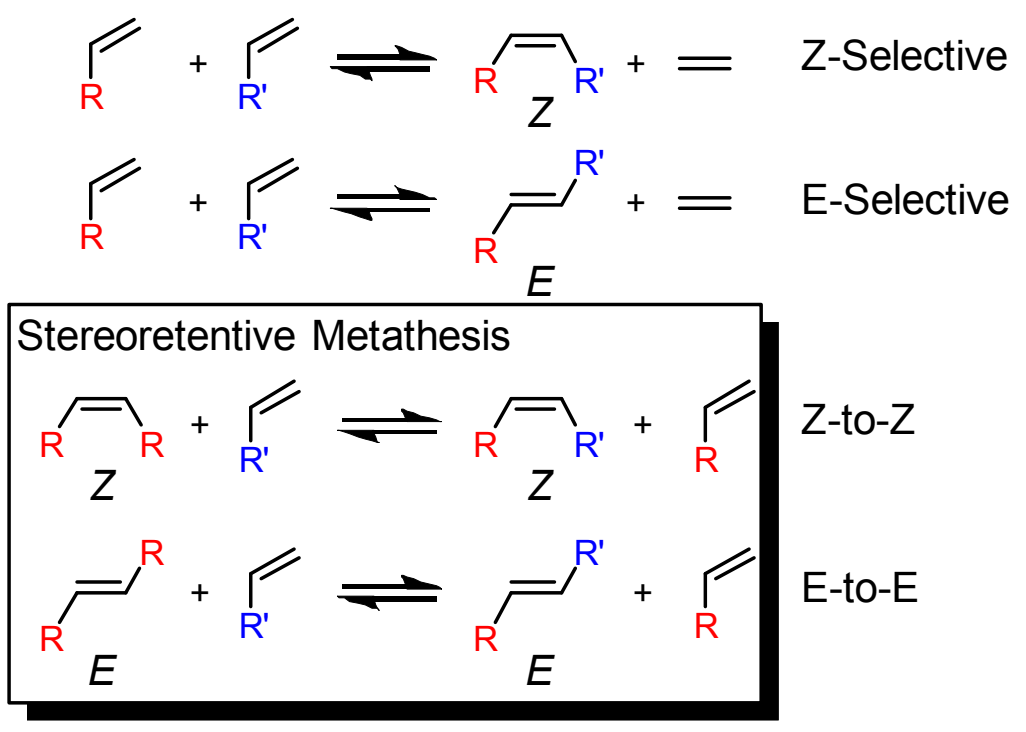

Figure 1. Models of stereoselective olefin metathesis (other work) and stereoretentive olefin metathesis (this work)

The report from Grubbs examined the reactivity and selectivity of these catalysts to form $E$ olefins. ${ }^{7}$ While catalyst 1 showed low yields for most cross-metathesis reactions with $E$-internal olefins, the reactions produced new products with complete retention of the starting olefin stereochemistry (Table 1). The yields of cross-metathesis reactions were improved by altering the NHC structure to that of catalyst $4^{7}$ While the yields are modest, the $>99: 1$ selectivity of $\mathbf{4}$ for stereoretention with $E$-alkenes is unprecedented. The proposed model that explains the retention of stereochemistry is shown in Figure $2 \mathrm{~b}$. For these dithiolate containing catalysts, a side-bound mechanism is proposed. ${ }^{4,8}$ Therefor, the plane of the metallacycle (in the ruthenacyclobutane intermediate) is perpendicular to the NHC ligand and the substituents at the $\alpha$ - and $\alpha$ '-positions of the metallacycle are forced down to avoid steric repulsions with the $N$-aryl groups. Due to these ligand-metallacycle steric interactions, if a $Z$-olefin reacts, the substituent at the $\beta$-position also points down (i.e. away from the NHC) and a new $Z$-olefin is generated. If an $E$-olefin reacts, the substituent at the $\beta$-position points up and a new $E$-olefin is generated. There is presumably no intrinsic preference for the $\beta$-substituent to be up or down based on this model. 
(a)
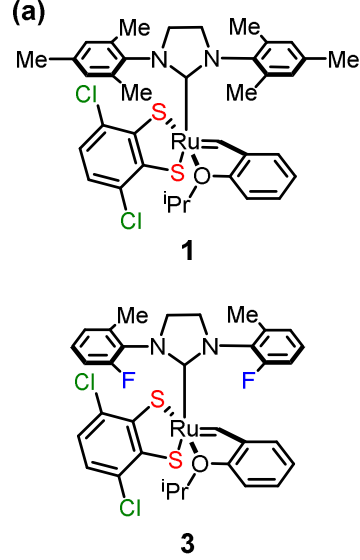
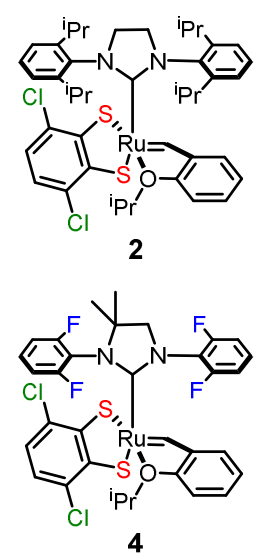

(b) Model for stereoretentive metathesis

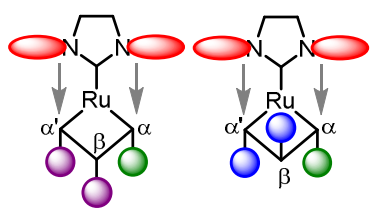

Figure 2. (a) catalysts examined by the Grubbs group for stereoretentive metathesis; (b) models for stereoretentive metathesis with Z-olefins (purple) and $E$-olefins (blue).

Table 1. Stereoretentive Cross-Metathesis Using Ruthenium Catalysts 1 and 4. $^{7}$

\begin{tabular}{cccc} 
Stereochemistry $_{1} \begin{array}{c}\text { of Starting } \\
\text { Olefin }\end{array}$ & Catalyst & Yield & $\begin{array}{c}\text { Product } \\
E: Z\end{array}$ \\
\hline$Z$ & $\mathbf{1}$ & $55 \%$ & $<1: 99$ \\
\hline$E$ & 1 & $7 \%$ & $>99: 1$ \\
\hline$Z$ & $\mathbf{4}$ & $42 \%$ & $<1: 99$ \\
\hline$E$ & 4 & $19 \%$ & $>99: 1$ \\
\hline
\end{tabular}

We examined the origins of stereoretentive metathesis with catalyst $\mathbf{4}$ using computational methods. We have probed the ligand effects on stereoselectivity and examined the steric environment of the NHC ligand and the steric repulsions of the NHC ligand with substituents at both the $\alpha$ - and $\beta$-positions of the metallacycle. Since catalyst $\mathbf{4}$ is a promising prototype of a kinetically $E$-selective catalyst, these computational insights can assist in the design of a kinetically $E$-selective metathesis catalyst.

\section{Computational Methods}

All calculations were performed using Gaussian 09. ${ }^{9}$ Geometry optimizations and frequency calculations were performed at the $\mathrm{B}^{2} \mathrm{LYP}^{10}$ level using LANL2DZ for ruthenium and 6-31G(d) for all other atoms. Zero point vibrational energies, thermal corrections, and entropies were computed from frequency calculations with a standard state of $298 \mathrm{~K}$ and $1 \mathrm{~atm}$. Quasiharmonic oscillator approximations were used to compute the entropic contributions to the Gibbs free energies, as discussed by Truhlar. ${ }^{11}$ Single point energy calculations were performed 
at the M06 ${ }^{12}$ level using SDD for ruthenium and $6-311+G(d, p)$ for other atoms with the SMD $^{13}$ continuum solvent model for THF.

\section{Results and Discussion}

Our first goal was to determine if the metathesis with catalyst $\mathbf{4}$ proceeds through a bottom-bound mechanism, in which the olefin approaches trans to the NHC ligand, or a sidebound mechanism, in which the olefin approaches cis to the NHC (Figure 3). ${ }^{4 a, 6,14}$ While Hoveyda and coworkers explored the side-bound mechanism in references $4 \mathrm{a}$ and 6 , a direct computational comparison of the bottom-bound and side-bound mechanisms has not been performed computationally for this class of catalysts. We have therefor begun our computational studies by examining both the bottom-bound and side-bound mechanisms. In order to completely understand the selectivity of these catalysts and design new catalysts, this comparison of mechanisms must be made. Using $\mathbf{5}$ as a model for the active ethylidene complex of catalyst $\mathbf{4}$, and $E$ - and $Z$-butene as substrates, we calculated all isomeric transition states for both bottombound and side-bound mechanisms. A graphical representation of the computed activation free energies is shown in Figure 4. In all cases, the side-bound transition states (blue) are lower in energy than the bottom-bound transition states (red). To adopt a bottom-bound mechanism, the ortho-dithiolate ligand must orient one of the sulfur atoms trans to the alkylidene. Such geometry is strongly destabilized due to trans-influence of the thiolate on the alkylidene. ${ }^{15} \mathrm{~A}$ large distortion of the ligand sphere is also required to accommodate the incoming olefin in the bottom-bound mechanism. In typical bottom-bound metathesis transition states (e.g. with the second generation Grubbs catalyst), 16 the alkylidene prefers to be positioned directly under the $N$-alkyl group. In the bottom-bound transition states (5Db and $\mathbf{5 F b}$ ), the $\mathrm{C}_{\mathrm{ipso}}-\mathrm{N}-\mathrm{Ru}-\mathrm{C}_{\text {alkyliene }}$ dihedrals (red-highlighted atoms in $\mathbf{5 D b}$ and $\mathbf{5 F b}$ ) are $>50^{\circ}$. The bottom-bound pathway is disfavored in all cases due to a combination of trans influences and steric effects.

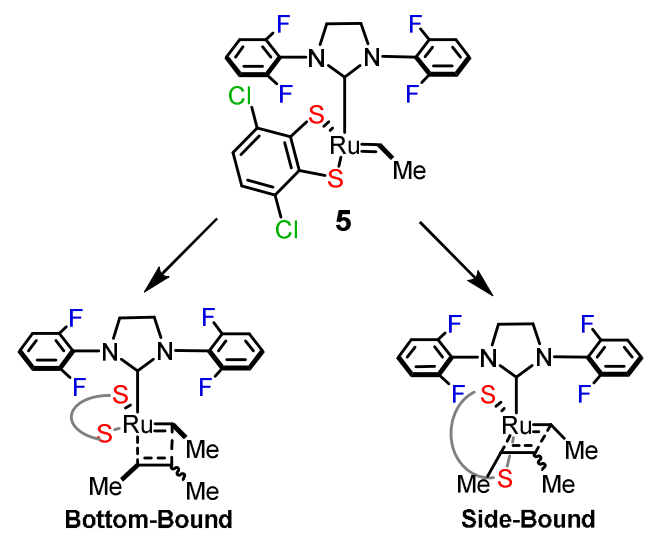

Figure 3. Possible mechanistic pathways for reactions of 5 with butene. 


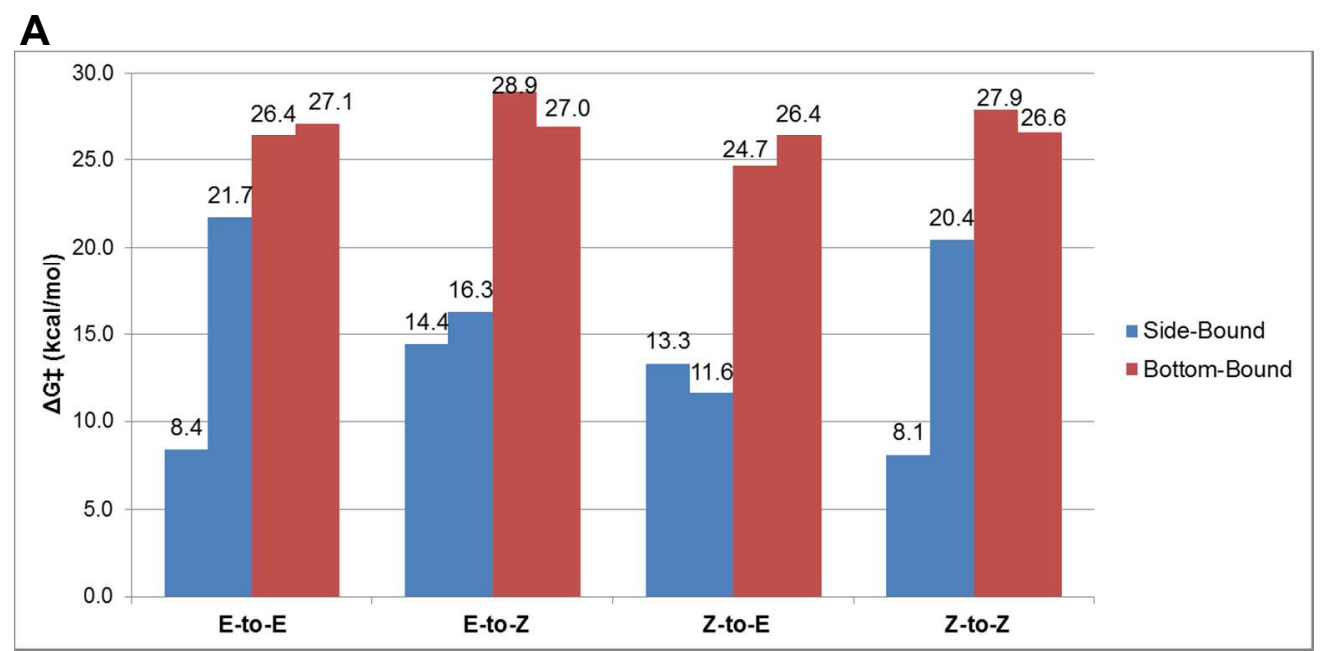

B
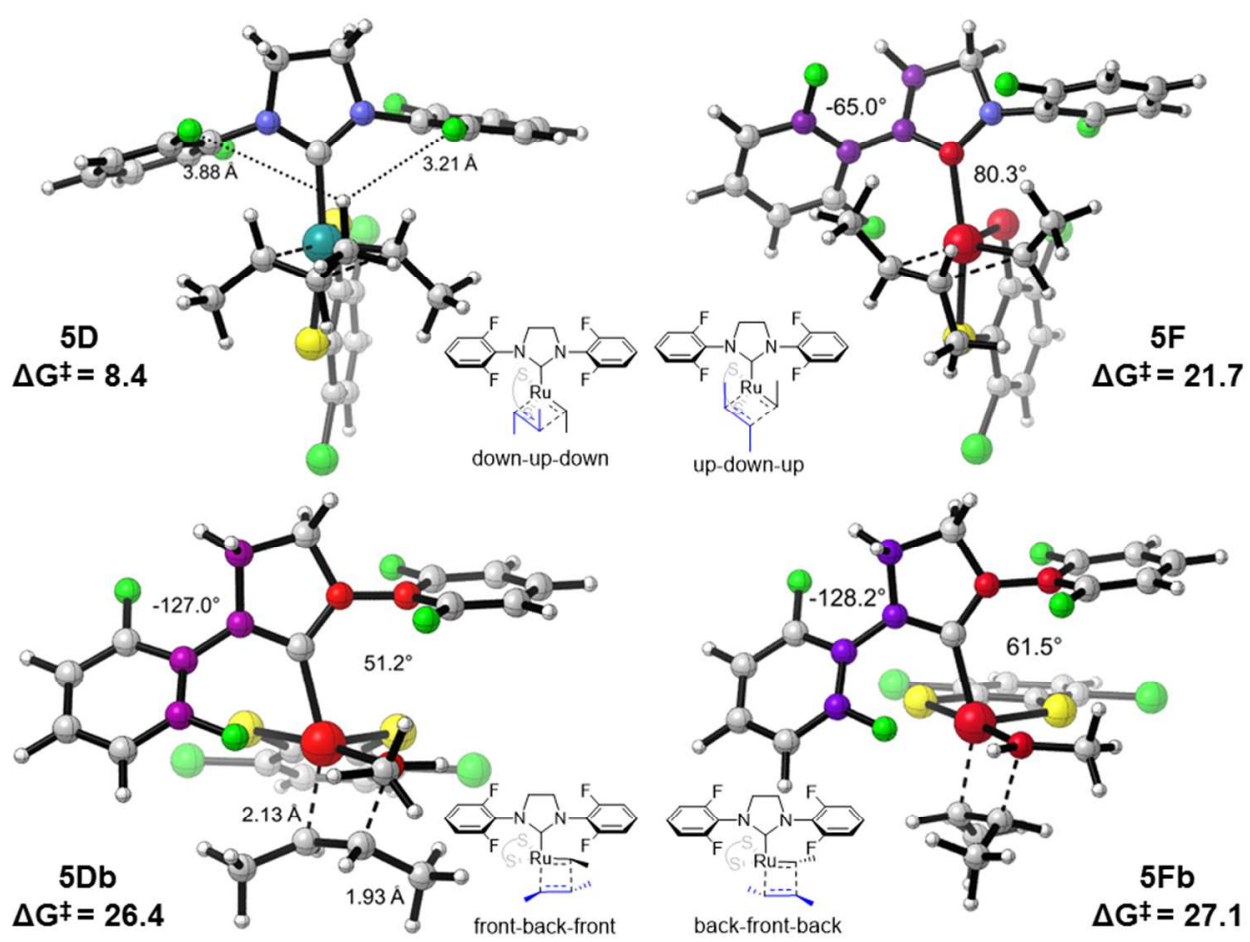

Figure 4. (A) Barriers to formation of ruthenacyclobutane (TS1). There are 2 retention pathways (E-to-E and Z-to-Z) and 2 inversion pathways (E-to-Z and Z-to-E) which are represented on the $\mathrm{X}$-axis. Each pathway has 4 possible approaches, 2 side-bound (blue columns) and 2 bottombound (red columns). (B) Transition structures of the 4 approaches for E-to-E metathesis. Sidebound pathways (5D and $\mathbf{5 F}$ ) are shown on the top while bottom-bound pathways (5Db and $\mathbf{5 F b )}$ are shown on the bottom.

In the favored side-bound pathway, Figure 4 shows that the stereoretentive pathways for both $E$ - and $Z$-olefins are lower in activation free energy than the corresponding stereoinversion pathways by $>3-6 \mathrm{kcal} / \mathrm{mol}$. For the reaction of $Z$-butene with $\mathbf{5}$, the preferred mode of addition is to have all substituents on the forming metallacycle pointing down, away from the sterically demanding NHC (5A, Figure 5). After the retro-[2+2] cycloaddition of the trisubstituted 
metallacycle, this process leads to retention of the starting Z-olefin stereochemistry. As shown in Figure 5, the two possible pathways leading to $E$-butene both require much higher activation energies. If the Z-butene adds with both substituents "up" (5C), this costs an additional +3.5 $\mathrm{kcal} / \mathrm{mol}$ compared to $\mathbf{5 A}$ and induces significant steric repulsion between the $N$-aryl substituent on the NHC and the a' substituent on the forming metallacycle. The left $\mathrm{N}$-aryl group must distort out of the way of the incoming alkene. If the olefin adds "down" and the alkylidene is pointing up (5B), there is a $+5.2 \mathrm{kcal} / \mathrm{mol}$ activation free energy penalty compared to $\mathbf{5 A}$ due to the direct steric clash of the alkylidene with the $\mathrm{N}$-aryl group, evidenced by the short distance between the $\mathrm{H}$ atom on the alkylidene and the ortho-F atom on the NHC N-aryl group (2.29 $\AA$ ). Due to these steric penalties, the retentive pathway is strongly favored, leading to exclusive formation $Z$-olefins.

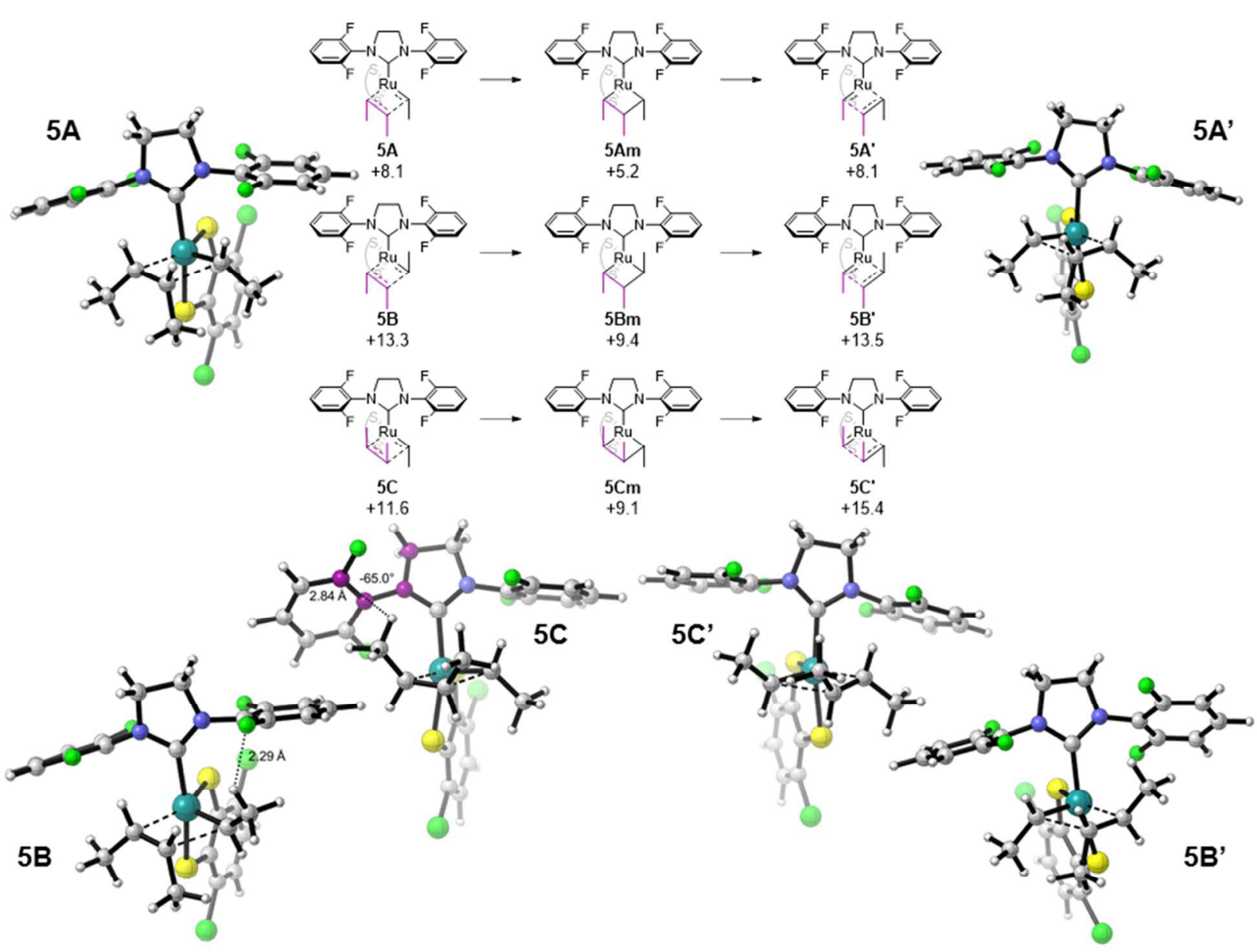

Figure 5. [2+2] cycloaddition $(\mathbf{5 A}-\mathbf{C})$ and retro-[2+2] cycloaddition (5A'-C') transition structures and ruthenacyclobutane intermediates $(\mathbf{5 A m - 5 C m})$ and respective Gibbs free energies of activation for the lowest energy $Z$-retentive pathway (A) and 2 possible stereoinversion pathways $(\mathbf{B}, \mathbf{C})$ for the reaction of $\mathbf{5}$ with Z-butene. All energies are Gibbs free energies in $\mathrm{kcal} / \mathrm{mol}$ with respect to the separated reactants $\mathbf{5}$ and Z-butene. The other $Z$-retentive pathway with all three metallacycle substituents pointing up requires much higher activation energy $\left(\Delta G^{*}\right.$ $=20.4 \mathrm{kcal} / \mathrm{mol}$ ) and is not shown. 
In the reaction with $E$-olefin, at least one substituent on the forming metallacycle must point up towards the NHC. The least sterically demanding position for a substituent to point up towards the NHC is the $\beta$-position of the forming metallacycle (shown in blue spheres in Figure $2 b)$. Figure 6 shows the computed reaction pathways for $E$-butene. The lowest energy pathway (5D) is one in which there is only one substituent, at the $\beta$-position, points towards the NHC and leads to retention of olefin stereochemistry. Due to similar steric effects as in the reactions with Z-olefins, pointing the alkylidene up (5C') or reversing the olefin approach (5B') incurs activation free energy penalties. This leads to a $6.0 \mathrm{kcal} / \mathrm{mol}$ preference for retention and exclusive formation of a new $E$-olefin when reacting with an $E$-olefin.

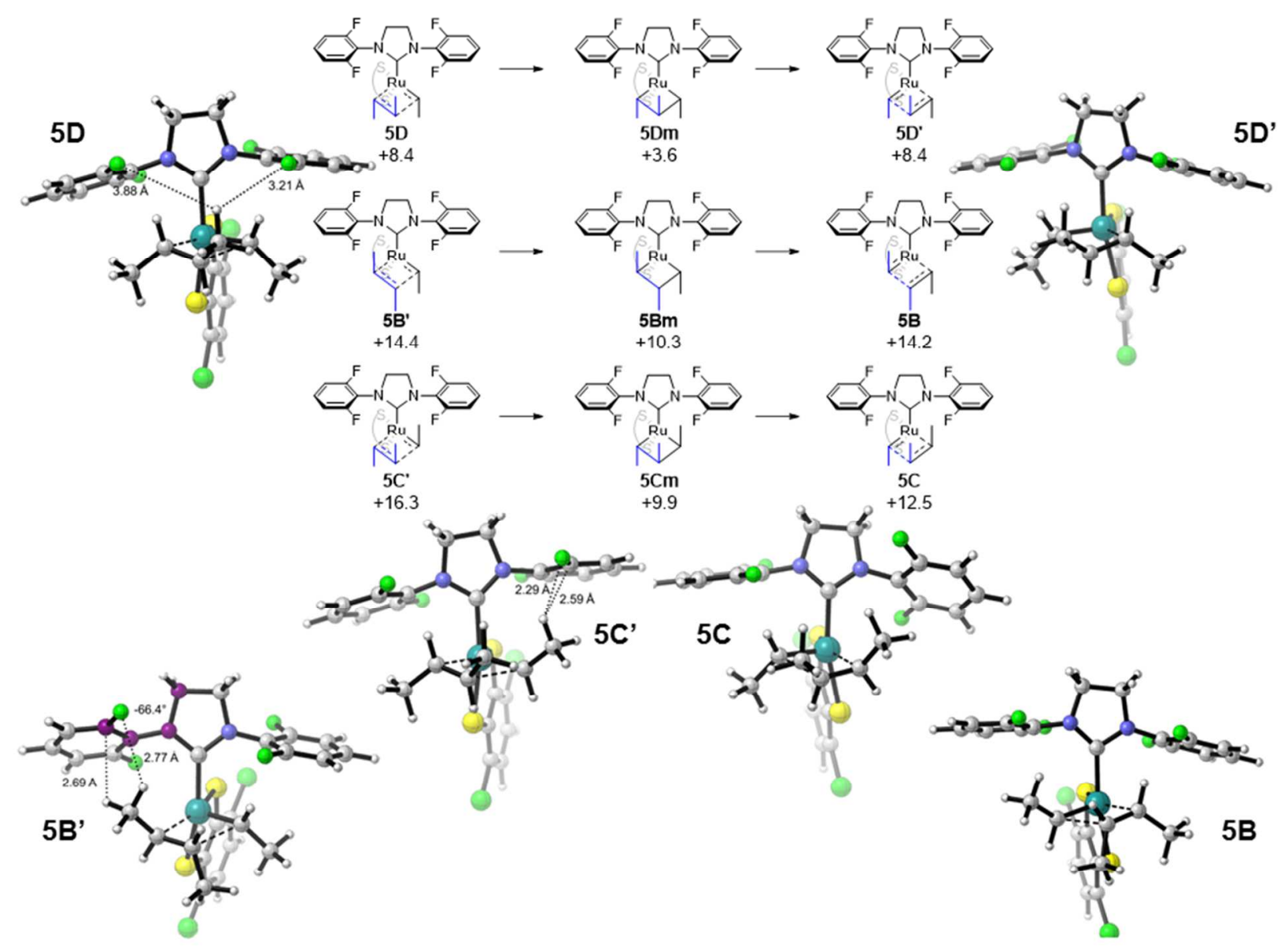

Figure 6. $[2+2]$ cycloaddition $\left(5 \mathbf{D}, \mathbf{5 B}\right.$ ', 5C') and retro-[2+2] cycloaddition $\left(5 \mathbf{D}^{\prime}, \mathbf{5 B}, \mathbf{5 C}\right)$ transition structures and ruthenacyclobutane intermediates $(\mathbf{5 D m}, \mathbf{5 B m}, \mathbf{5 C m})$ and respective Gibbs free energies of activation for the lowest energy $E$-retentive pathway (D) and 2 possible stereoinversion pathways $(\mathbf{B}, \mathbf{C})$ for the reaction of $\mathbf{5}$ with $E$-butene. All energies are Gibbs free energies in $\mathrm{kcal} / \mathrm{mol}$ with respect to the separated reactants $\mathbf{5}$ and $E$-butene. The other $E$-retentive pathway with the $\alpha$ and $\alpha$ ' substituents of the metallacycle substituents pointing up requires a much higher activation energy $\left(\Delta \mathrm{G}^{\sharp}=21.7 \mathrm{kcal} / \mathrm{mol}\right)$ and is not shown.

The analysis of transition state isomers in Figure 6 revealed the design principles for $E$ selective metathesis catalyst: the $N$-aryl substituents on the NHC ligand should maximize the steric repulsions with the a-substituent on the metallacycle while still allowing the $\beta$-substituent 
to point up towards the NHC ligand. Thus, a few factors, including the steric properties of the $N$ aryl group as well as the NHC backbone substituents, are expected to affect the E/Z selectivity. To gain deeper insights into the steric environment of the NHC ligand and the steric interactions with the olefin and alkylidene substituents, we plotted the $2 \mathrm{D}$ steric contour maps ${ }^{17}$ of catalyst 4 . The ligand steric contour map is derived from the van der Waals surface of the NHC ligand from the optimized structures of the ethylidene complex $\mathbf{6}$ and the lowest-energy ruthenacyclobutane intermediates 6Dm and 6Am in the lowest energy $E$ - and $Z$-retentive pathways, respectively. The contour map was created following the previously reported procedure. ${ }^{17 \mathrm{~g}}$ The NHC ligand is rotated and translated so that the $\mathrm{Ru}$ atom is placed at the origin of the Cartesian coordinate system and the $z$-axis is oriented along the $\mathrm{Ru}-\mathrm{C}$ (carbene) bond. The contour line of zero is drawn through all points on the van der Waals surface having the same $z$ coordinate as the $\mathrm{Ru}$ atom. The positive contour lines (colored in green and blue) indicate regions on the ligand van der Waals surface having a positive $z$ coordinate, i.e. more distant from the plane of the ruthenacyclobutane. Yellow and red indicate regions closer to the ruthenacyclobutane where more significant ligand-substrate steric clashes are expected.

To examine the conformational change of the NHC ligand along the $E$ - and $Z$-retentive pathways, steric contour maps of the same NHC ligand in the ethylidene complex 6 and the two ruthenacyclobutanes featuring a "down-up-down" (6Dm) and "down-down-down" (6Am) substitution patterns on the metallacycle are plotted in Figure 7. In ethylidene complex 6, one of the $N$-2,6-difluorophenyl groups is significantly tilted due to flexibility of the $N$-aryl bond. ${ }^{18}$ This tilted $N$-aryl conformation creates a relatively sterically demanding pocket between the two ortho-F substituents (see the red and orange regions near the "closed" pocket on the contour map of 6). In the metallacycle intermediates, the $N$-aryl group rotates away from the metallacycle, as indicated by the disappearance of the red and orange regions on the contour plot. This conformational change creates a much larger "open" pocket between the two ortho-F substituents to accommodate the $\beta$-substituent. To our surprise, the ligand conformation in $6 \mathrm{Dm}$ and $6 \mathbf{A m}$ are remarkably similar. The "open" pocket above the $\beta$-substituent is present regardless if the $\beta$ substituent is pointing up or down. A closer inspection of the geometries of the metallacycles revealed that the $N$-aryl groups in both 6Dm and 6Am are slightly tilted away from the metallacycle due to the steric repulsions with the hydrogen atoms at the a- and a'-positions. This steric effect also distorts the NHC ligand towards the dithiolate: the $\mathrm{S}-\mathrm{Ru}-\mathrm{C}$ (carbene) bond angle is decreased from $94.8^{\circ}$ in ethylidene 6 to $87.7^{\circ}$ and $86.8^{\circ}$ in $6 \mathrm{Dm}$ and $\mathbf{6 A m}$ respectively. This distortion also contributes to the formation of the "open" pocket above the $\beta$-substituent in 6Dm and 6Am. Due to the formation of this "open" pocket, the steric repulsions between the NHC ligand and the $\beta$-substituent in 6Dm are diminished. The "down-down-down" isomer 6Am becomes $3.6 \mathrm{kcal} / \mathrm{mol}$ less stable than the "down-up-down" isomer $6 \mathrm{Dm}$ because of the repulsion between the adjacent methyl groups on the metallacycle in $6 \mathrm{Am}$. 


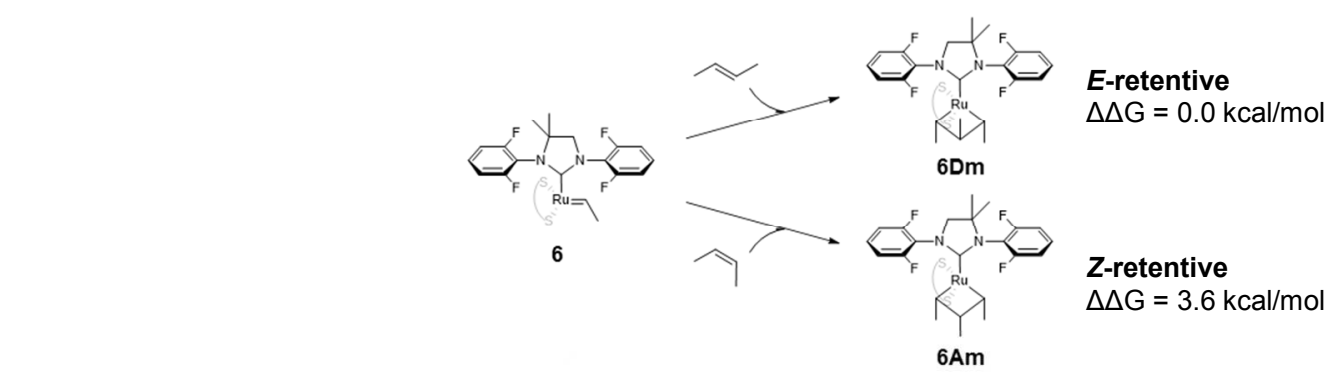

$\int_{-2}^{3}$

Ligand Steric Contour

\section{Front View}
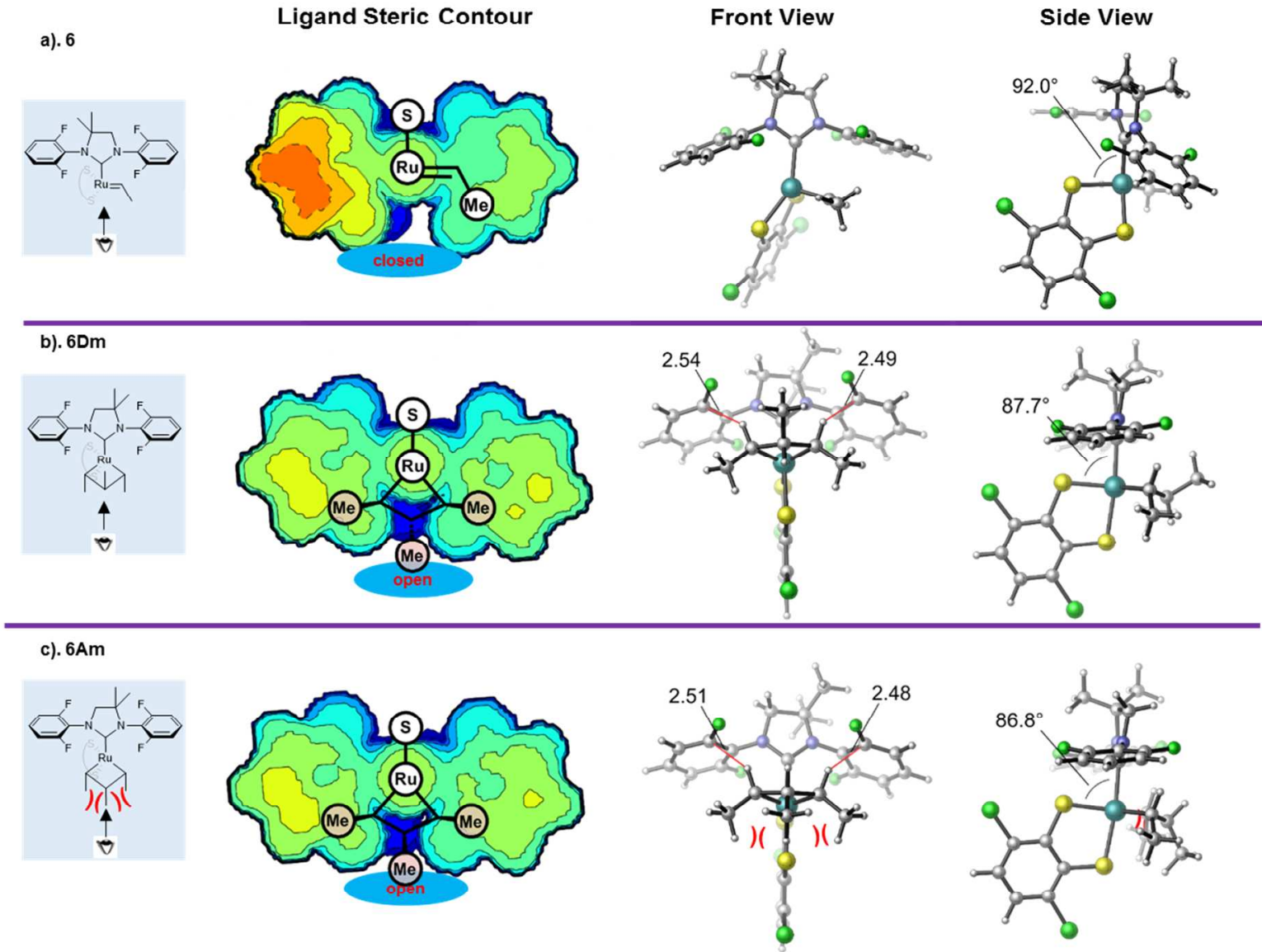

Figure 7. Ligand steric contour maps of (a) ethylidene complex 6, ruthenacyclobutane intermediates (b) 6Dm and (c) 6Am. The open pocket above the $\beta$-Me substituent promotes both $E$ - and $Z$ - retentive pathways.

We also investigated the origin of the reactivity difference between catalysts $\mathbf{1}$ and $\mathbf{4}$ in the $Z$ - and $E$-retentive metathesis. In these studies, we used the complete NHC ligand for catalyst 4 with the germinal dimethyl substituted backbone (as in 6). The rate-limiting transition states for the $Z$ - and $E$-retentive pathways of both catalysts are shown in Table 2 . The rate-limiting steps for both pathways are more than $2 \mathrm{kcal} / \mathrm{mol}$ lower in activation free energy with catalyst 4 (6A \& 6D) than with 1 (7A \& 7D), suggesting 4 is a more reactive catalyst in reactions with both $E$ - and $Z$-olefins. The lower reactivity of $\mathbf{1}$ is due to the presence of the more hindering orthomethyl groups of the SIMes ligand which cause more steric repulsion with the incoming olefins than the ortho-F groups on catalyst 4. 
Table 2. Rate-limiting transition structures for the retention pathways with catalysts $\mathbf{4}$ and $\mathbf{1}$.

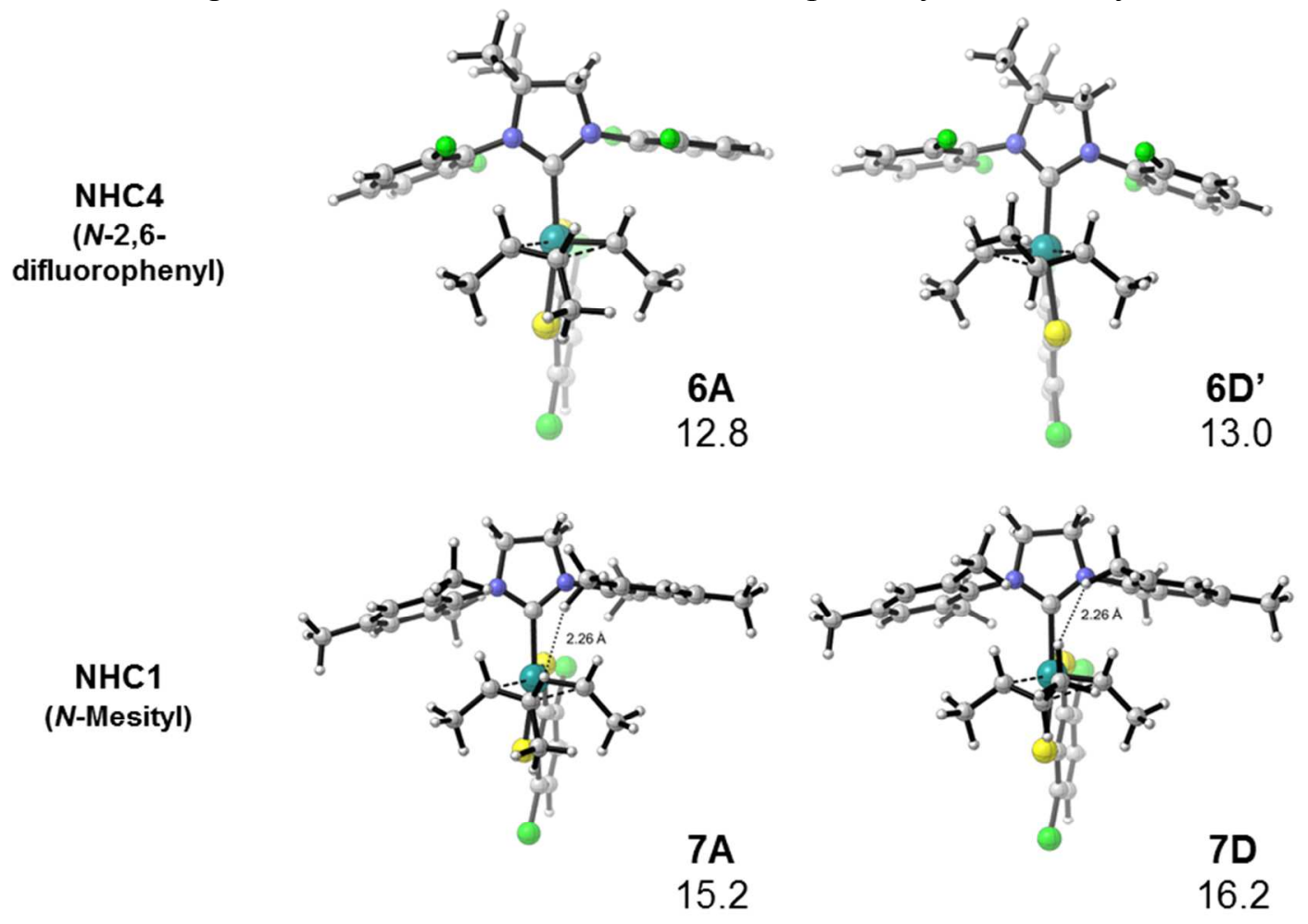

To examine the ligand steric environment in catalyst $\mathbf{1}$, we plotted the steric contour maps of the active alkylidene complex 7 and ruthenacyclobutane intermediates 7Dm and 7Am in the $E$ - and $Z$-retentive pathways (Figure 8). The steric contour maps show that, similar to the reactions with complex 6 in Figure 7, an "open" pocket is created above the $\beta$-substituent in both ruthenacyclobutane intermediates $\mathbf{7 D m}$ and $\mathbf{7 A m}$. Again, the formation of this open pocket is due to the steric repulsions with the hydrogen atoms at the $a-$ and a'-positions of the metallacycle. Compared to the ortho-F substituted catalyst 1, the ortho-Me groups on catalyst 4 lead to greater repulsions with the metallacycles in both 7Dm and 7Am. This is evidenced by the greater distortion of the NHC ligand towards the dithiolate: the $\mathrm{S}-\mathrm{Ru}-\mathrm{C}$ (carbene) bond angle is $84.2^{\circ}$ and $83.2^{\circ}$ in $7 \mathbf{D m}$ and $7 \mathbf{A m}$, respectively, even smaller than the $\mathrm{S}-\mathrm{Ru}-\mathrm{C}$ (carbene) angle in 6Dm and 6Am $\left(87.7^{\circ}\right.$ and $86.8^{\circ}$, respectively). These results are in agreement with transition structures above that catalyst 1 is highly $E$ - and $Z$-retentive due to the open pocket above the $\beta$ position on the metallacycle. However, the reactivity of catalyst $\mathbf{1}$ is lower than that of $\mathbf{4}$ due to stronger steric repulsions with the metallacycle in the side-bound pathways. 
a). 7
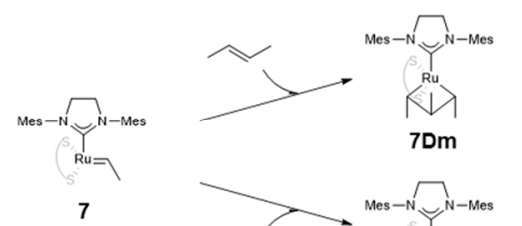

E-retentive

$\Delta \Delta \mathrm{G}=0.0 \mathrm{kcal} / \mathrm{mol}$

\section{Ligand Steric Contour}

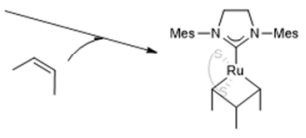

Z-retentive $\Delta \Delta \mathrm{G}=3.0 \mathrm{kcal} / \mathrm{mol}$
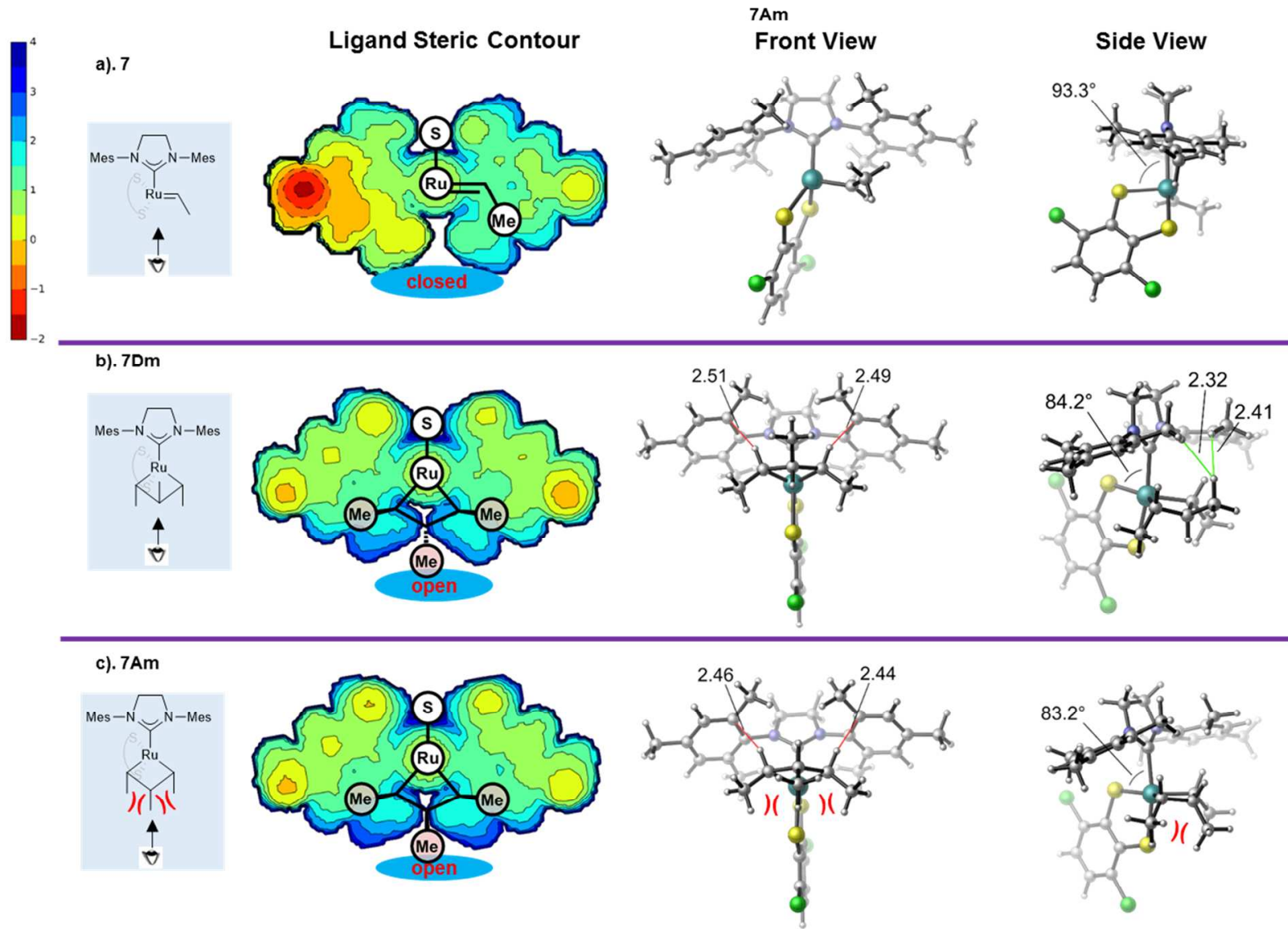

Figure 8. Ligand steric contour maps of (a) ethylidene complex 7, ruthenacyclobutane intermediates (b) 7Dm and (c) 7Am.

\section{Conclusion}

In conclusion, we have performed computational studies on the stereoretentive olefin metathesis using dithiolate-ligated ruthenium catalysts $\mathbf{1}$ and $\mathbf{4}$ to understand their reactivity and selectivity in the cross-metathesis with $E$ - and $Z$-olefins. We have confirmed that the substituents at the $\alpha$-positions of the forming metallacycle prefer to point away from the NHC ligand, while the $\beta$-substituents may point either away or towards the NHC without incurring significant steric clashes with the NHC ligand, as proposed by Grubbs and co-workers. ${ }^{7}$ These ligand-controlled steric interactions enforce the retention of the original olefin stereochemistry in metathesis. DFToptimized transition structures and ligand steric contour maps revealed the important role of the steric interactions between the NHC ligand and the hydrogen atoms at the $\alpha$ - and $\alpha$ '-positions of 
the metallacycle. Such interactions tilt the $N$-aryl group on the NHC ligand and create an "open" pocket above the $\beta$-position of the metallacycle, which can accomdate a substituent pointing towards the NHC ligand. This "open" pocket is critical for the stereoselectivity in the $E$-retentive metathesis. The DFT calculations also revealed the effects of ligand-metallacycle steric interactions on reactivity. The $N$-mesityl substituted catalyst $\mathbf{1}$ is slightly less reactive than the 2,6-difluorophenyl substituted catalyst 4 due to the unfavorable steric repulsions between the bulkier $N$-mesityl groups and the metallacycle in the side-bound metathesis pathway.

\section{SUPPORTING INFORMATION}

Further computational details and Cartesian coordinates with corresponding energetic information are available in the Supporting Information (SI).

\section{Author Information}

*pengliu@pitt.edu,*houk@chem.ucla.edu

\section{Notes}

The authors declare no competing financial interests.

\section{Acknowledgements}

This work was supported by the Office of Naval Research (N00014-14-1-0650). This work used computational resources for projects TG-CHE040013N and TG-CHE140139 in the Extreme Science and Engineering Discovery Environment (XSEDE), ${ }^{19}$ which is supported by National Science Foundation grant number ACI-1548562, and computational resources provided by the UCLA IDRE Hoffman2 cluster. All 3-dimensional images were made using CYLview. ${ }^{20}$

\section{References}

1 For discussion and examples of typical metathesis reactions, see the following: (a) Fürstner, A. Science 2013, 341, 1357- 1364. (b) Lee, C. W.; Grubbs, R. H. Org. Lett. 2000, 2, 2145-2147. (c) Meng, D.; Su, D.; Balog, A.; Bertinato, P.; Sorensen, E. J.; Danishefsky, S. J.; Zheng, Y.; Chou, T.; He, L.; Horwitz, S. B. J. Am. Chem. Soc. 1997, 119, 2733-2734. (d) Fürstner, A.; Langemann, K. Synthesis 1997, 792-803. (e) Trnka, T. M.; Grubbs, R. H. Acc. Chem. Res. 2001, 34, 18. (f) Schrock, R. R.; Hoveyda, A. H. Angew. Chem., Int. Ed. 2003, 42, 4592. (g) Vougioukalakis, G. C.; Grubbs, R. H. Chem. Rev. 2010, 110, 1746. (h) Montogomery, T. P.; Ahmed, T. S.; Grubbs, R. H. Angew. Chem. Int. Ed. doi:10.1002/anie.201704686.

2 See the following reviews for a discussion of Z-selective catalysts: (a) Herbert, M. B.; Grubbs, R. H. Angew. Chem. Int. Ed. 2015, 54, 5018-5024. (b) Hoveyda, A. H. J. Org. Chem. 2014, 79, 4763-4792. (c) Marx, V. M.; Rosebrugh, L. E.; Herbert, M. B.; Grubbs, R. H. Cyclometalated Ruthenium Alkylidene Complexes: A Powerful Family of Z-Selective Olefin Metathesis Catalysts. In Ruthenium in Catalysis. Dixneuf, P. H., Bruneau, C., Eds.; Topics in Organometallic Chemistry; Springer International Publishing: Switzerland, 2014; 48, 1-17.

3 Mo-based catalysts have been developed and discussed here: (a) Nguyen, T. T.; Koh, M. J.; Shen, X.; Romiti, F.; Schrock, R. R.; Hoveyda, A. H. Science 2016, 352, 569-575. (b) Shen, X.; Nguyen, T. T.; Koh, M. J.; Xu, D.; Speed, A. X. H.; Schrock, R. R.; Hoveyda. A. H. Nature 2017, 541, 380

4 (a) Khan, R. K. M.; Torker, S.; Hoveyda, A. H. J. Am. Chem. Soc. 2013, 135, 10258-10261. (b) Koh, M. J.; Khan, R. K. M.; Torker, S.; Hoveyda, A. H. Angew. Chem. Int. Ed. 2014, 53, 1968-1972.

5 (a) Nelson, J. W.; Grundy, L. M.; Dang, Y.; Wang, Z.-X.; Wang, X. Organometallics 2014, 33, 4290-4294. (b) Dahcheh, F.; Stephan, D. W. Organometallics 2013, 32, 5253-5255. (c) McKinty, A. M.; Stephan, D. W. Dalton Trans. 2014, 43, 2710-2712. (d) Dahcheh, F.; Stephan, D. W. Dalton Trans. 2015, 44, 1724-1733.

6 Koh, M. J.; Khan, R. K. M.; Torker, S.; Yu, M.; Mikus, M. S.; Hoveyda, A. H. Nature 2015, 517, $181-186$.

7 Johns, A. M.; Ahmed, T. S.; Jackson, B. W.; Grubbs, R. H.; Pederson, R. L. Org. Lett. 2016, 18, $772-775$. 
8 For a comparison of bottom-bound and side-bound mechanisms with other catalyst see: Liu, P.; Xu, X.; Dong, X.; Keitz, B. K.; Herbert, M. B.; Grubbs, R. H.; Houk, K. N. J. Am. Chem. Soc. 2012, 134, 1464-1467

9 Frisch, M. J.; Gaussian 09, Revision D.01; Gaussian, Inc.: Wallingford CT, 2009. (see Supplemental Information for full reference)

10 (a) Becke, A. D. Phys. Rev. A 1988, 38, 3098-3100. (b) Becke, A. D. J. Chem. Phys. 1993, 98, 5648- 5652. (c) Lee, C.; Yang, W.; Parr, R. G. Phys. Rev. B 1988, 37, 785- 789.

11 (a) Zhao, Y.; Truhlar, D. G. Phys. Chem. Chem. Phys. 2008, 10, 2813-2818. (b) Ribeiro, R. F.; Marenich, A. V.; Cramer, C. J.; Truhlar, D. G. J. Phys. Chem. B. 2011, 115, 14556-14562.

12 (a) Zhao,Y.; Truhlar, D. G. Theor. Chem. Acc. 2008, 120, 215-241. (b) Zhao, Y.; Truhlar, D. G. Acc. Chem. Res. 2008, 41, 157-167.

13 Marenich, A. V.; Cramer, C. J.; Truhlar, D. G. J. Phys. Chem. B 2009, 113, 6378-6396.

14 See computations on bottom-bound vs. side-bound mechanisms for chelated Z-selective Ru catalysts: Liu, P.; Xu, X.; Dong, X.; Keitz, B. K.; Herbert, M. B.; Grubbs, R. H.; Houk, K. N. J. Am. Chem. Soc. 2012, 134, 1464-1467.

15 For more information on the trans influence, please refer to the following references: (a) Appleton, T. G.; Clark, H. C.; Manzer, L. E. Coord. Chem. Rev. 1973, 10, 335- 422. (b) Coe, B. J.; Glenwright, S. J. Coord. Chem. Rev. 2000, 203, 5-80. (b) Mikus, M. S.; Torker, S.; Xu, C.; Li, B.; Hoveyda, A. H. Organometallics 2016, 35, 3878-3892. 16 For examples of DFT studies with Grubbs second generation catalysts see the following: (a) Mathew, J.; Suresh, C. H. Organometallics 2011, 30, 3106-3112. (b) Nuñez-Zarur, F.; Solans-Monfort, X.; Rodríguez-Santiago, L.; Pleixats, R.; Sodupe, M. Chem. Eur. J. 2011, 17, 7506-7520. (c) Śliwa, P.; Kurleto, K.; Handzlik, J.; Rogalski, S.; Żak, P.; Wyrzykiewicz, B.; Pietraszuk, C. Organometallics 2016, 35, 621-628. (d) Remyam P. R.; Suresh, C. H. J. Comput. Chem. 2017, 38, 1704-1711. (e) Rybáčková, M.; Hošek, J.; Šimůnek, O.; Kolaříková, V.; Kvíčala, J. Beilstein J. Org. Chem. 2015, 11, 2150-2157. (f) Adlhart, C.; Chen, P. J. Am. Chem. Soc. 2004, 126, 3496-3510.

17 (a) Wucher, P.; Caporaso, L.; Roesle, P.; Ragone, F.; Cavallo, L.; Mechking, S.; Gottker-Schnetmann, I.; Proc. Natl. Acad. Sci. USA. 2011, 108, 8955-8959; (b) Liu, P.; Montgomery, J.; Houk, K. N. J. Am. Chem. Soc. 2011, 133, 6956-6959.; (c) Hong, X.; Liu, P.; Houk, K. N. J. Am. Chem. Soc. 2013, 135, 1456-1462; (d) Wang, T.; Yu, Z.; Hoon, D. L.; Huang, K. -W.; Lan, Y.; Lu. Y. Chem. Sci. 2015, 6, 4912-4922; (e) Huang, G.; Liu, P. ACS. Catal. 2016, 6, 809-820; (f) Falivene, L.; Credendino, R.; Poater, A.; Petta, A.; Serra, L.; Oliva, R.; Scarano, V.; Cavallo, L. Organometallics. 2016, 35, 2286-2293; (g) Wang, H.; Lu, G.; Sormunen, G. J.; Malik, H. A.; Liu, P.; Montgomery, J. J. Am. Chem. Soc.; doi: 10.1021/jacs.7b04583

18 Ragone F.; Poater A.; Cavallo L. J. Am. Chem. Soc. 2010, 132, 4249-4258

19 Reference supplied in Supporting Information (SI)

20 Legault, C. Y. CYLview, 1.0b; Université de Sherbrooke: Sherbrooke, QC, Canada, 2009; http://www.cylview.org.

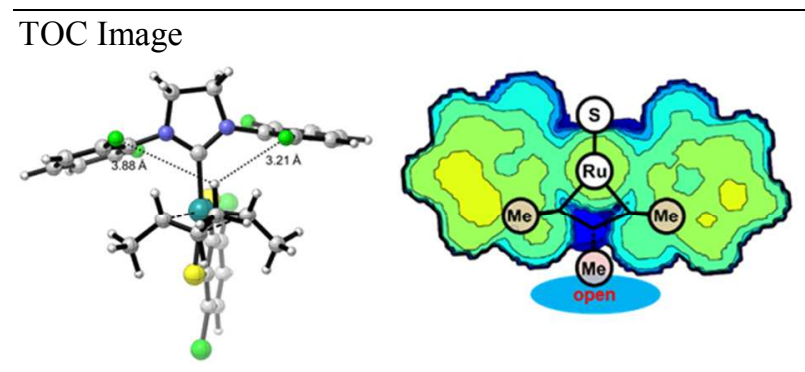

